\title{
Verified Numerical Computations and Related Applications
}

\author{
Shin'ichi Oishi
}

\begin{abstract}
The author has been engaged in the study of numerical computations with result verification starting from 1990 .
\end{abstract}

\section{Summary}

The author has been engaged in the study of numerical computations with result verification starting from 1990. As a result, the following results have been obtained:

1. We have proposed a concept of error-free transformations for calculating not only approximate values of numerical evaluations of certain arithmetic expressions consisting of additions, subtractions and multiplications, but also exact error of such numerical evaluations. Using this concept, we have established the way of getting numerical solutions for various problems in numerical linear algebra with required accuracy. Especially, we have established the verified numerical methods for the following problems:

a. Finite dimensional linear equations including extremely ill-conditioned problems.

b. Matrix eigenvalue problems.

2. We have proposed various verified numerical methods for various problems including

a. Calculation of ill-conditioned definite integrals.

b. Boundary value problems for nonlinear differential equations based on invention of methods for eigenvalue evaluation of associated linearized problems.

In this talk, we will review some of these results and will mention possible applications for cryptography.

\footnotetext{
S. Oishi $(\bowtie)$

Waseda University, 3-4-1 Okubo, Tokyo, Shinjuku-ku 169-8555, Japan

e-mail: oishi@waseda.jp

(C) The Author(s) 2021

T. Takagi et al. (eds.), International Symposium on Mathematics, Quantum Theory, and Cryptography, Mathematics for Industry 33, https://doi.org/10.1007/978-981-15-5191-8_4
} 
Open Access This chapter is licensed under the terms of the Creative Commons Attribution 4.0 International License (http://creativecommons.org/licenses/by/4.0/), which permits use, sharing, adaptation, distribution and reproduction in any medium or format, as long as you give appropriate credit to the original author(s) and the source, provide a link to the Creative Commons license and indicate if changes were made.

The images or other third party material in this chapter are included in the chapter's Creative Commons license, unless indicated otherwise in a credit line to the material. If material is not included in the chapter's Creative Commons license and your intended use is not permitted by statutory regulation or exceeds the permitted use, you will need to obtain permission directly from the copyright holder.

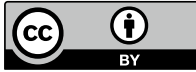

